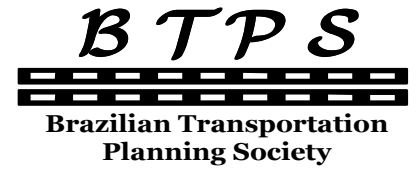

\author{
Journal of Transport Literature \\ Vol. 8, n. 1, pp. 109-124, Jan. 2014 \\ Research Directory
}

JTL | RELIT

www.transport-literature.org

\title{
Competição entre o ônibus e o avião no transporte interestadual de passageiros na Região Metropolitana de Belo Horizonte
}

\author{
[Competition between coaches and airlines in the \\ interstate transportation market in the metropolitan region of Belo Horizonte, Brazil] \\ Iara Cristina P. L. Paiva*, Carlos Müller \\ Instituto Tecnológico de Aeronáutica - Brasil
}

Submitted 14 Jun 2012; received in revised form 7 Jul 2012; accepted 15 Oct 2012

\begin{abstract}
Resumo
No Brasil, há uma forte concorrência entre o ônibus e o avião no transporte interestadual de passageiros para algumas rotas, principalmente se não houver uma diferença muito grande no preço da passagem dos dois modais. O presente trabalho visa a analisar a competição entre esses modais no transporte de passageiros com origem ou destino na Região Metropolitana de Belo Horizonte. Foram analisados alguns fatores que afetam o aumento (ou a queda) de passageiros de ônibus, como o rendimento da população e a concorrência com o transporte aéreo. Os resultados encontrados poderão servir de base para que os operadores de ônibus possam estudar como aumentar sua atratividade. Para ajudar os operadores na precificação do ônibus, além da elasticidade-preço própria do ônibus, foi estimada uma elasticidade-preço cruzada intermodal. Os resultados mostram que com um aumento de $1 \%$ no preço da passagem do ônibus, perde-se cerca de 1,4\% de passageiros.
\end{abstract}

Palavras-Chave: ônibus, competição, transporte interestadual, passageiros.

\begin{abstract}
In the interstate transportation of passengers in Brazil, there is a strong competition between bus and airplane for some routes, especially if there is not a big difference in the fare of the two modes. This study aims to examine the competition between these transportation modes in the metropolitan area of Belo Horizonte. It uses a multiple regression model that considers the restriction at the Pampulha airport (flight transfer from Pampulha to Confins). Some factors affecting the increase (or decrease) of bus passengers were analyzed, such as the population income and the competition with air travel. These results can be used by bus operators as a study base on how to increase their business' attractiveness. To assist operators with the bus fare pricing, the intermodal cross-elasticity was estimated besides the bus fare price elasticity itself. The results show that operators lose about $1.4 \%$ of bus passengers as they increase the fare in $1 \%$.
\end{abstract}

Key words: bus, competition, interstate transportation, passengers.

*Email: iaracplp@gmail.com.

\section{Recommended Citation}

Paiva, I. C. and Müller, C. (2014) Competição entre o ônibus e o avião no transporte interestadual de passageiros na Região Metropolitana de Belo Horizonte. Journal of Transport Literature, vol. 8, n. 1, pp. 109-124.

- JTL/RELIT is a fully electronic, peer-reviewed, open access, international journal focused on emerging transport markets and published by BPTS - Brazilian Transport Planning Society. Website www.transport-literature.org. ISSN 2238-1031.

This paper is downloadable at www.transport-literature.org/open-access. 


\section{Introdução}

O presente trabalho tem como objetivo analisar a competição entre o avião e o ônibus nas viagens interestaduais que tem como origem ou destino a Região Metropolitana de Belo Horizonte. Para isso, foi utilizado um modelo de regressão múltipla usando como variável dependente a demanda por viagens no mercado rodoviário interestadual de passageiros. Foram analisados alguns fatores que afetam o aumento (ou a queda) de passageiros, como o rendimento da população e a concorrência com o transporte aéreo. Os resultados encontrados podem ser usados como base para que os operadores de ônibus possam estudar como aumentar sua atratividade. Por exemplo, através da redução de preços.

No Brasil, os principais meios de transporte públicos utilizados em viagens são o avião e o ônibus, já que o transporte ferroviário e hidroviário não atendem todo o país. Antigamente, somente pessoas de alto poder aquisitivo podiam viajar de avião. Nos dias de hoje, grande parte da população, inclusive quem pertence às classes $\mathrm{C}$ e $\mathrm{D}$, utiliza esse meio de transporte, devido aos preços mais acessíveis e à facilidade de crédito. Por isso, a concorrência entre avião e ônibus aumentou muito nas viagens interestaduais, que são viagens geralmente longas. Quanto mais longa a viagem, mais competitivo se torna o avião com relação ao ônibus.

Muitos fatores, além do preço e da distância de viagem, podem fazer com que o usuário prefira um modal ao invés do outro. Algumas estradas brasileiras não apresentam boas condições, o que pode criar insegurança para os passageiros. Por outro lado, muitos aeroportos brasileiros tem operado acima da sua capacidade, o que pode causar atrasos e desconforto ao passageiro devido à superlotação do terminal. No entanto, esses fatores são difíceis de ser quantificados e modelados. Os principais aeroportos e rodovias do país passam por processos de concessão para empresas privadas, e com isso, espera-se que a infraestrutura dos dois modais sofram melhorias.

Leal et al. (2009) analisa a concorrência entre o avião e o ônibus no transporte interestadual de passageiros no Brasil de acordo com o nível de renda entre cidades e de acordo com a relação custo-benefício entre os modos de transporte. Os autores comprovam que quanto 
maior a distância e o tempo de viagem de ônibus, maior a participação de mercado do transporte aéreo. Além disso, quanto menor for a diferença de preço entre os dois modais, maior a participação de mercado do avião. Turolla et al. (2008), também analisam a competição entre esses dois modais no Brasil e concluem que apesar de a indústria de ônibus ser um forte cartel, ela é sensível às tarifas aéreas. Em períodos de descontos nas passagens aéreas, o ônibus pode perder muitos passageiros em viagens de longa distância.

Dependendo da rota, compensa muito mais viajar de avião do que de ônibus, pois praticamente não há diferença de preço entre os dois modais. Para competir com o transporte aéreo, as empresas de transporte rodoviário começaram a lançar promoções por compra com antecedência, descontos no par de bilhetes (ida e volta) e serviços de milhagem, assim como já é feito com as passagens aéreas. Além disso, as vendas pela internet facilitaram a compra de passagens de ônibus.

Para planejar eficientemente o sistema de ônibus interestadual, além de se estudar a sua competição com outros meios de transporte, deve-se conhecer muito bem a sua demanda. $\mathrm{O}$ presente trabalho não aplica uma modelagem para previsão de demanda, no entanto, Gonçalves et al. (2007) apresentam modelos econométricos de previsão de demanda do transporte rodoviário interestadual no Brasil. Com isso, podem ser estimados os volumes de movimentação nesse modal.

Em outro estudo, Gonçalves et al. (2006) realizam uma pesquisa sócio-econômica em algumas ligações entre cidades brasileiras e com isso, puderam obter um perfil dos usuários do transporte interestadual por ônibus nessas ligações. Os resultados da pesquisa mostraram que, em suas decisões de viagem, os usuários atribuem um peso forte à tarifa, ao conforto e ao tempo. Segundo os autores, o maior desejo dos usuários é "não andar de ônibus "pinga-pinga" e não andar de ônibus convencional" (p. 11). Os autores também observaram que mais de $50 \%$ dos entrevistados gostariam de viajar mais e que $40 \%$ desses declararam que não o fazem devido ao alto valor da tarifa.

Esse trabalho está assim dividido: a Seção 1 caracteriza a Região Metropolitana de Belo Horizonte (RMBH) e descreve o transporte interestadual por ônibus e por avião nessa região. A Seção 2 apresenta a metodologia utilizada e a Seção 3 analisa os resultados encontrados. Ao final, as conclusões do trabalho são apresentadas. 


\section{Transporte interestadual da RMBH}

A Região Metropolitana de Belo Horizonte (RMBH), ou Grande Belo Horizonte, é constituída de 34 municípios sendo a terceira maior aglomeração urbana do Brasil, com cerca de 5,4 milhões de habitantes, atrás apenas das regiões metropolitanas de São Paulo e Rio de Janeiro (IBGE, 2010).

A cidade de Belo Horizonte (BH) é a sexta cidade mais populosa do país (IBGE, 2010), com população de aproximadamente 2,4 milhões de habitantes. O município de $\mathrm{BH}$ tem o quinto maior PIB (Produto Interno Bruto) do Brasil (IBGE, 2008) e possui IDH (Índice de Desenvolvimento Humano) elevado (PNUD, 2000). Muitas viagens do país têm como origem ou destino a RMBH, pois, além de BH ser a capital de Minas Gerais, é uma região populosa e um importante centro de negócios e indústrias do país. As indústrias metalúrgica, automobilística, petroquímica e alimentícia tem grande importância para a economia da região. Uma parte do quadrilátero ferrífero, que é a principal área produtora de minério de ferro no Brasil, se situa na RMBH.

\subsection{Concorrência Intermodal entre o ônibus e o avião}

Uma pessoa proveniente da RMBH deve percorrer longas distâncias para sair do estado de Minas Gerais. A cidade de Belo Horizonte, por exemplo, dista aproximadamente $590 \mathrm{~km}$ da cidade de São Paulo, $440 \mathrm{~km}$ da cidade do Rio de Janeiro, 520 km de Vitória e 716 km de Brasília, a capital nacional. Por isso, existe forte concorrência entre ônibus e avião como meios de transporte em viagens interestaduais na $\mathrm{RMBH}$.

No Brasil, o ônibus era a principal modalidade para viagens interestaduais e internacionais. O transporte rodoviário regular foi responsável por cerca de $71 \%$ do total dos deslocamentos interestaduais e internacionais de passageiros em comparação com o aéreo em 2008 (ANTT, 2008). No entanto, em 2011, o número de passageiros de avião superou o de viajantes de ônibus interestaduais pela primeira vez no país (Folha de São Paulo, 2011). De 2002 a 2010, o número de passageiros de avião cresceu $115 \%$ e o de passageiros de ônibus caiu $31 \%$. 
Além dos preços baixos oferecidos pelas companhias aéreas, o ônibus perde atratividade em trechos operados por uma única empresa. Sem concorrência, pode haver uma piora na qualidade de serviço e na frequência de serviço e um aumento abusivo de preços, se comparado a um mercado em que há competição. De acordo com Moreira (2010), apenas uma empresa de transporte rodoviário opera a rota de Belo Horizonte a Salvador, um dos principais destinos na alta temporada. Já no transporte aéreo, seis companhias disputam os passageiros. O resultado é que a passagem de ida e volta de avião chega a ser 27,6\% mais barata do que a passagem de ônibus.

\subsection{1 Ônibus interestadual}

O terminal rodoviário de Belo Horizonte (Terminal Rodoviário Governador Israel Pinheiro) foi inaugurado em 1971 e tem capacidade para atender a uma demanda de 17 milhões de passageiros por ano. De acordo com a Prefeitura de Belo Horizonte, o terminal recebe diariamente, em média, 40 mil pessoas, considerando-se embarques e desembarques. Desde junho de 2003 o terminal é administrado pela Prefeitura de Belo Horizonte.

O ônibus é utilizado como meio de transporte mesmo em viagens de longa distância. O trajeto de ônibus interestadual mais longo, saindo do terminal rodoviário de Belo Horizonte, é para Porto Velho, a $3.074 \mathrm{~km}$.

De acordo com a ANTT (2011), 39,3\% das pessoas que utilizam o transporte rodoviário interestadual na ligação Belo Horizonte - São Paulo viajam a trabalho, 37,9\% viajam para visitar parentes e 26,4\% viajam a lazer ou turismo. Na Tabela 1 pode-se observar que a maioria das pessoas viaja mensal, trimestral ou anualmente (em um total de quase 60\%). Somente $14 \%$ dos passageiros viaja menos de uma vez por ano - o que mostra que a maioria dos passageiros viajam com uma certa frequência. 


\section{Tabela 1 - Frequência de viagens na ligação Belo Horizonte - São Paulo ${ }^{1}$}

\begin{tabular}{lc}
\hline Frequência de viagens & Percentual \\
\hline Diária & $0,00 \%$ \\
Mais de uma vez por semana & $2,86 \%$ \\
Semanal & $3,57 \%$ \\
Quinzenal & $6,43 \%$ \\
Mensal & $15,71 \%$ \\
Trimestral & $15,71 \%$ \\
Semestral & $9,29 \%$ \\
Anual & $26,43 \%$ \\
Menos de uma vez por ano & $14,29 \%$ \\
Não respondeu & $5,71 \%$ \\
\hline
\end{tabular}

\subsubsection{Transporte aéreo}

Os principais aeroportos da RMBH são os aeroportos de Pampulha (sigla: PLU ou SBBH) e Confins (sigla: CNF ou SBCF). O aeroporto de Pampulha (Aeroporto Carlos Drummond de Andrade) fica a aproximadamente oito quilômetros do centro de Belo Horizonte. Em 2011, apresentou movimentação de quase 800 mil passageiros, sendo que ele tem capacidade de receber 2,2 milhões $^{2}$ de passageiros por ano, de acordo com a Infraero.

O aeroporto de Confins (Aeroporto Internacional Tancredo Neves) recebe voos internacionais e a maioria dos vôos domésticos. Ele foi construído na década de 80, e encontra-se na Região Metropolitana de Belo Horizonte, nos municípios de Confins e Lagoa Santa, a $38 \mathrm{~km}$ do centro da capital de Minas Gerais. Em 2011, apresentou movimentação de aproximadamente 9,5 milhões de passageiros, sendo que ele tem capacidade de receber 10,1 milhões de passageiros por ano, de acordo com a Infraero.

Devido à distância maior de $\mathrm{BH}$ e à acessibilidade ruim, o aeroporto de Confins estava sendo subutilizado, até 2005, enquanto o aeroporto de Pampulha estava lotado (em 2004 apresentou movimento de mais de 3 milhões passageiros, mas tem capacidade para 2,2 milhões). $\mathrm{O}$ aeroporto da Pampulha é preferível para os passageiros com origem ou destino em BH devido à facilidade de acesso. No entanto, Pampulha é muito menor que Confins. Comparando-se o tamanho dos dois, o terminal de passageiros do aeroporto de Pampulha tem $4.500 \mathrm{~m}^{2}$ enquanto o de Confins tem $60.000 \mathrm{~m}^{2}$. Além disso, em 2004, Confins registrou prejuízo

\footnotetext{
1 Fonte: ANTT, 2011

${ }^{2}$ Fonte: Infraero
} 
operacional de R\$ 7,5 milhões (Agência Minas, 2009). Em março de 2005 a Infraero transferiu mais de 120 voos do aeroporto da Pampulha para Confins, obrigando os passageiros a utilizar o aeroporto maior. Em Pampulha permanecem os voos privados e regionais.

Como pode ser observado na Tabela 2, o movimento de passageiros no Aeroporto Internacional de Confins cresceu 645\% entre 2004 e 2005 e cresceu $2.354 \%$ comparando-se 2004 com 2011. Já o aeroporto de Pampulha, apresentou uma queda de $60 \%$ na sua movimentação anual após a restrição do aeroporto, em 2005. Além disso, de acordo com a Agência Minas (2009), o lucro operacional de Confins aumentou 123\%, comparando-se o primeiro semestre de 2007 com o mesmo período de 2008.

Tabela 2 - Movimento anual de passageiros nos aeroportos de Pampulha e Confins ${ }^{3}$

\begin{tabular}{rrrrrrrrr}
\hline & 2004 & 2005 & 2006 & 2007 & 2008 & 2009 & 2010 & 2011 \\
\hline PLU & 3.194 .715 & 1.281 .745 & 800.940 & 759.824 & 561.189 & 598.360 & 757.685 & 793.305 \\
CNF & 388.580 & 2.893 .299 & 3.727 .501 & 4.340 .129 & 5.189 .528 & 5.617 .171 & 7.261 .064 & 9.534 .987 \\
\hline
\end{tabular}

\section{Metodologia}

Para a análise de concorrência intermodal entre o ônibus interestadual e o avião, foram obtidos diversos dados em sites da internet e posteriormente foi feito um estudo econométrico desses dados.

\subsection{Descrição dos dados}

A Figura 1 mostra a quantidade de passageiros transportados por ônibus interestadual em Minas Gerais de fevereiro de 1996 a julho de 2011, de acordo com a FIPE (Fundação Instituto de Pesquisas Econômicas). Pode-se observar que a quantidade de passageiros apresenta forte sazonalidade. O transporte perde passageiros até 2007 e, depois, a quantidade de passageiros volta a aumentar.

\footnotetext{
${ }^{3}$ Fonte: autores, com base em dados da Infraero.
} 


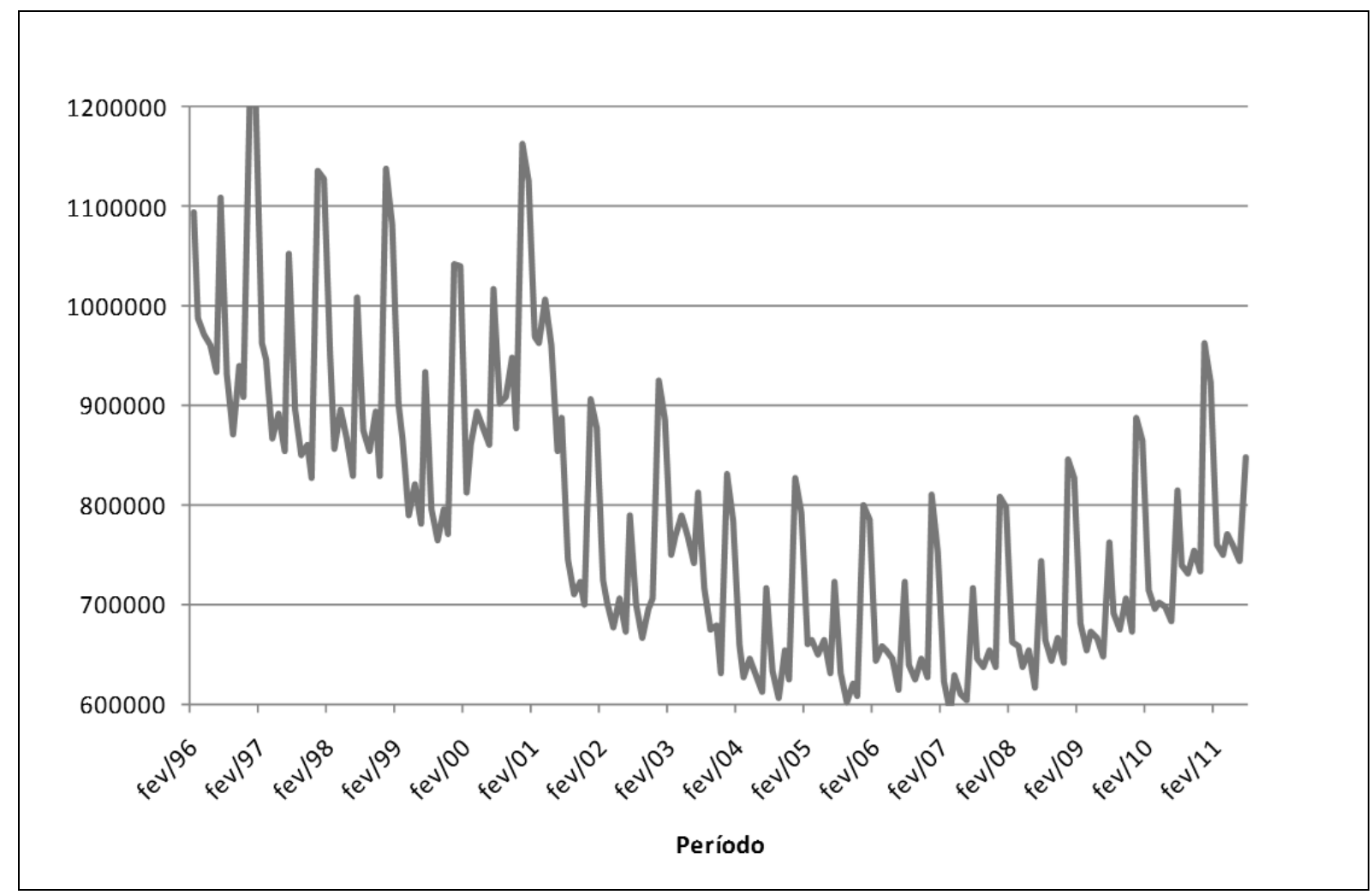

Figura 1 - Quantidade de passageiros transportados por ônibus interestadual ao longo do tempo em Minas Gerais ${ }^{4}$

Um banco de dados da FIPE, o Índice de Desempenho Econômico do Transporte (IDET), apresenta dados de diversos modais de transportes, tanto de passageiros quanto de carga. No caso do transporte rodoviário de passageiros, foi utilizada a técnica estatística de Amostragem Estratificada para a obtenção de informações. Para estratificar a população, foi feito um cadastro que descreve a população das empresas de transporte no Brasil, de modo a gerar uma amostra representativa da população compondo um painel fixo de empresas que fornecem informações mensais.

Através da multiplicação do rendimento médio real efetivo das pessoas ocupadas pela população ocupada na RMBH, obtidos no Ipeadata, encontrou-se a massa de rendimento. A Figura 2 mostra a massa de rendimento de março de 2002 a maio de 2010 em Reais de julho de 2011. Observa-se forte sazonalidade nos dados no mês de dezembro, provavelmente devido ao recebimento do décimo terceiro e ao período de férias de final de ano.

\footnotetext{
${ }^{4}$ Fonte: autores, com base nos dados da FIPE.
} 


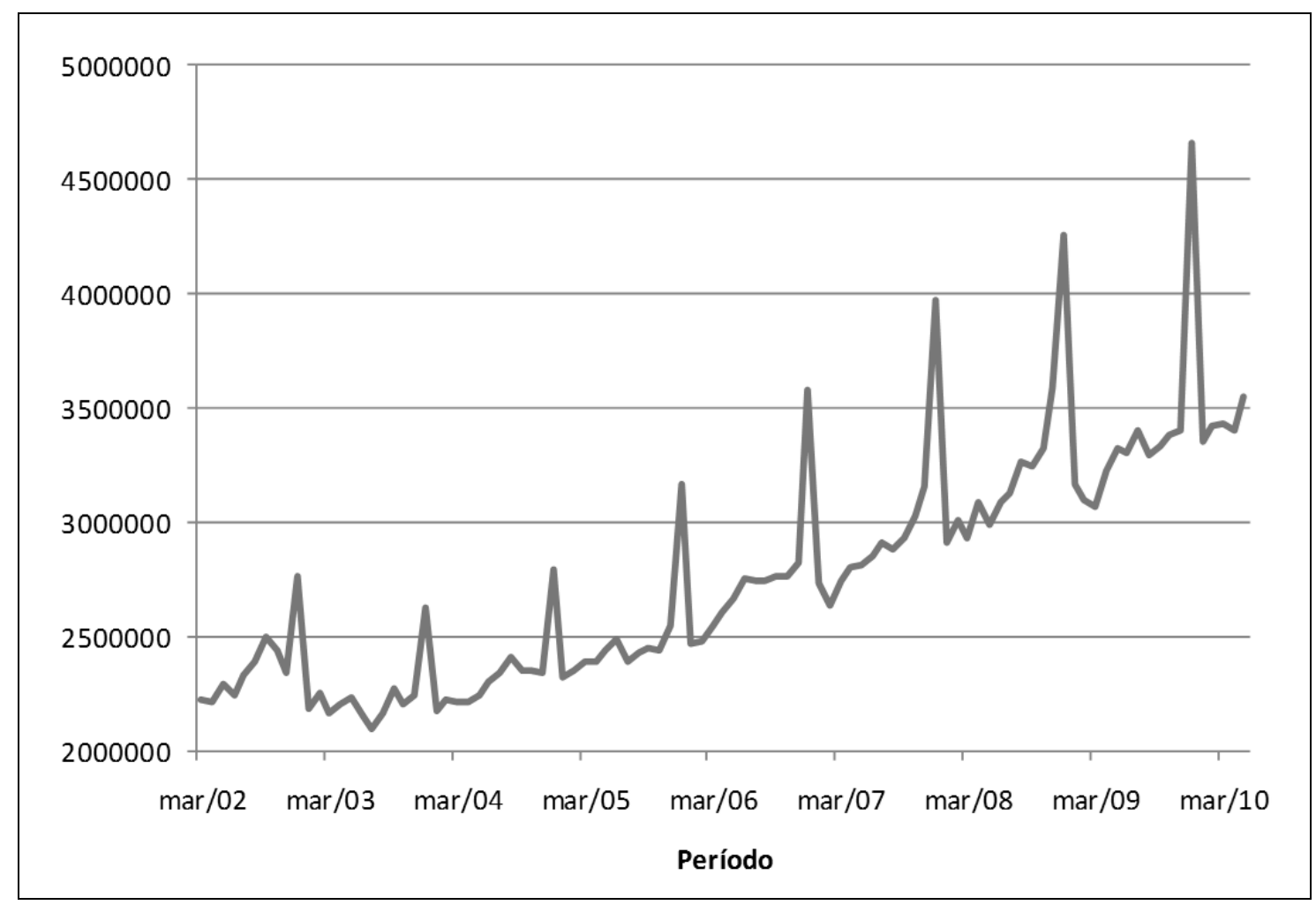

Figura 2 - Massa de rendimento ao longo do tempo para a $\mathrm{RMBH}^{5}$

A Tabela 3 apresenta um resumo dos dados de passageiros transportados em ônibus interestaduais e da massa de rendimento. A tabela apresenta algumas características das variáveis (variable) tais como, a quantidade de observações (obs), a média (mean), o desvio padrão (std. dev.), o valor mínimo ( $\min$ ) e valor máximo ( $\max$ ) das variáveis.

Tabela 3 - Resumo das variáveis de passageiros transportados e massa de rendimento ${ }^{6}$

\begin{tabular}{r|rrrrr} 
Variable & obs & Mean & Std. Dev. & Min & Max \\
\hline pax & 186 & 789039.2 & 142054.7 & 591373 & 1205786 \\
massa_rend & 99 & 2762000 & 506114.7 & 2101293 & 4660436
\end{tabular}

Outros dados obtidos para a análise econométrica foram a variação do preço de ônibus interestadual e de passagem aérea, de julho de 1999 a julho de 2011, e a variação do preço de itens relacionados a despesas pessoais, de fevereiro de 1996 a julho de 2011, para a RMBH no SIDRA. Essas variáveis não foram acrescentados na Tabela 3, pois não foram obtidos os valores exatos das variáveis, apenas a sua variação ao longo do tempo. Os itens de despesas pessoais se referem a serviços pessoais (em gastos com cabelereiro, sapateiro, manicure,

\footnotetext{
${ }^{5}$ Fonte: autores, com base nos dados do Ipeadata. Em R \$ constantes de julho de 2011.

${ }^{6}$ Fonte: autores, com base nos dados da FIPE e Ipeadata.
} 
barbeiro, empregado doméstico etc), recreação, fumo e fotografia (que são gastos com clube, cinema, ingressos para jogos, brinquedos, instrumentos musicais, cigarros, máquinas fotográficas etc), educação e leitura (inclui cursos, gastos com papelaria, jornais, revistas etc). Todas essas variáveis foram deflacionadas para julho de 2011.

Considera-se que o ônibus interestadual e as despesas pessoais são bens substitutos, ou seja, quando as despesas pessoais tem seu preço aumentado, as pessoas passam a viajar mais (ou mais pessoas viajam) de ônibus. Através da Figura 3 pode-se observar que quando as despesas pessoais tem um aumento no seu preço, e a quantidade consumida passa de $B$ para $B^{*}$, a reta de restrição orçamentária $(R O)$ rotaciona para baixo, e assim, o ônibus passa a ser mais utilizado (a quantidade consumida passa de $O$ para $O^{*}$ ). Isso ocorre pois a curva de indiferença $U$ passa a ser $U^{*}$ de modo que a quantidade de bens consumidos esteja de acordo com a nova reta de restrição orçamentária $\left(R O^{*}\right)$. A curva de indiferença representa todas as combinações de bens que fornecem o mesmo nível de satisfação para o consumidor.

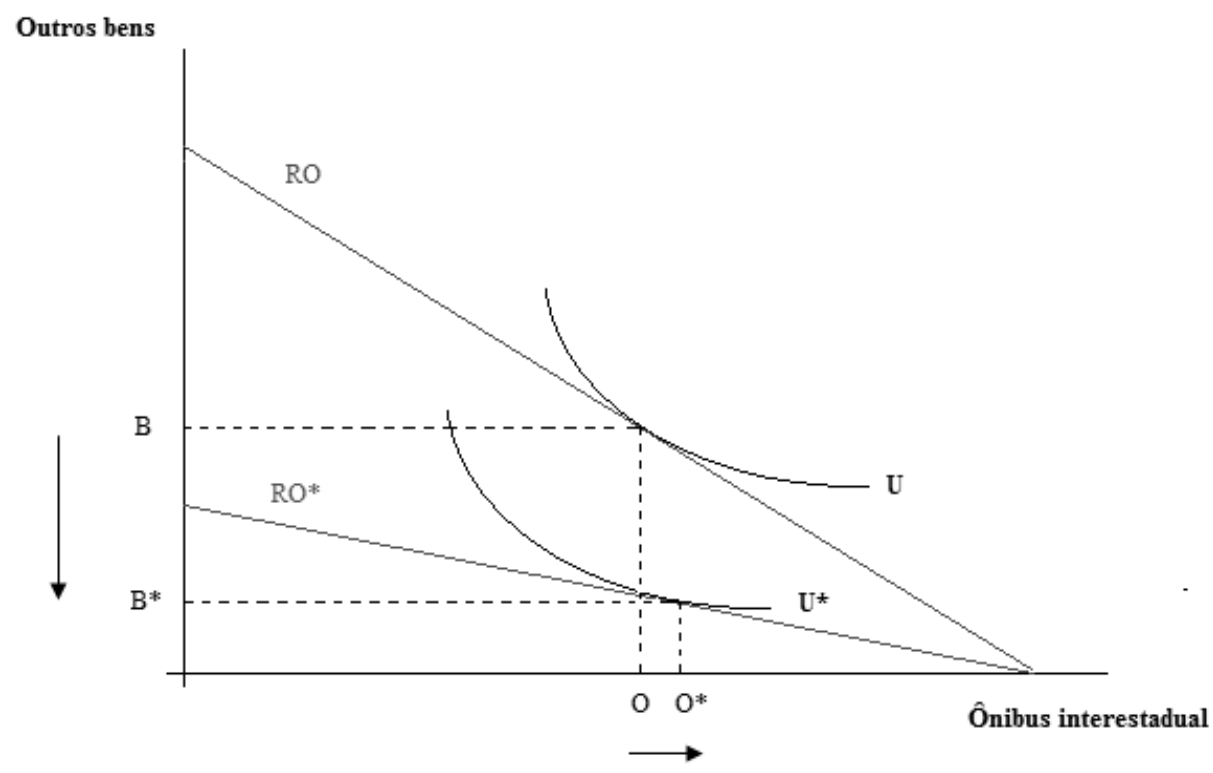

Figura 3 - Curva de indiferença 


\subsection{Modelo econométrico}

Para a análise da concorrência entre o ônibus e o avião no transporte interestadual de passageiros, foi utilizado um modelo de regressão múltipla. A variável dependente é o movimento de passageiros do ônibus interestadual (pax) e as variáveis independentes, descritas no item 2.1, são:

- massa_rend: massa de rendimento

- desp_pessoal: gastos com despesas pessoais

- passag_bus: preço da passagem de ônibus

- passag_aerea: preço da passagem aérea

Além disso, foram inseridas dummies para controlar a sazonalidade ( $m_{-} i$, sendo que $i$ é o índice do mês de 1 a 12) e a restrição do aeroporto da Pampulha (drestricao) em março de 2005. A Equação (1) apresenta o modelo econométrico especificado, em que os $\beta_{\mathrm{i}}$ representam os parâmetros populacionais e o $u$ é o termo de erro e representa os fatores nãoobserváveis. Assume-se que os fatores não-observáveis na população se distribuem em torno da média da mesma e que $u$ não tem correlação com os regressores. Ou seja, a média de $u$ é zero e independe do valor dos regressores.

$$
\begin{gathered}
\text { pax }=\beta_{0}+\beta_{1} \text { desp_pessoal }+\beta_{2} \text { massa_rend }+\beta_{3} \text { passag_bus }+\beta_{4} \text { passag_aerea } \\
+\beta_{5} \text { drestricao }+\sum_{i=2}^{12} \beta_{i+4} m \_i+u
\end{gathered}
$$

$\mathrm{Na}$ verdade, os coeficientes $\beta_{1}, \beta_{3}$ e $\beta_{4}$ não podem ser precisamente calculados pois os dados coletados não fornecem os valores exatos dessas variáveis. Sabe-se apenas a variação do seu preço ao longo do tempo. No entanto, esses coeficientes não são necessários para a análise dos resultados. O importante são as elasticidades, apresentadas na Seção 3, que não dependem do preço exato e sim da sua variação percentual. A Equação (2) mostra, como exemplo, a elasticidade preço (da passagem aérea) da demanda (de passageiros de ônibus interestadual).

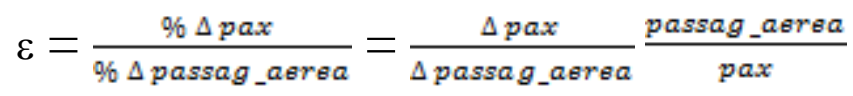




\section{Análise dos resultados}

A Tabela 4, obtida através de regressão linear, faz uma comparação entre três alternativas.

Tabela 4 - Resultados do modelo - especificações alternativas ${ }^{7}$

\begin{tabular}{|c|c|c|c|}
\hline & $\begin{array}{l}\text { (1) } \\
\operatorname{pax}\end{array}$ & $\begin{array}{l}(2) \\
\operatorname{pax}\end{array}$ & $\begin{array}{l}\text { (3) } \\
\operatorname{pax}\end{array}$ \\
\hline desp_pessoal & $\begin{array}{l}0.7044 * * \\
{[0.296]}\end{array}$ & & $\begin{array}{r}0.5141 \\
{[0.327]}\end{array}$ \\
\hline massa_rend & $\begin{array}{l}0.1887 * \\
{[0.102]}\end{array}$ & $\begin{array}{l}0.4105 * * * \\
{[0.051]}\end{array}$ & $\begin{array}{l}0.2354 * * \\
{[0.118]}\end{array}$ \\
\hline passag_bus & $\begin{array}{l}-1.3993 * * * \\
{[0.236]}\end{array}$ & $\begin{array}{l}-1.1268 * * * \\
{[0.206]}\end{array}$ & $\begin{array}{l}-1.1969 * * * \\
{[0.208]}\end{array}$ \\
\hline passag_aerea & $\begin{array}{l}0.1205 * \\
{[0.071]}\end{array}$ & $\begin{array}{r}0.0774 \\
{[0.072]}\end{array}$ & \\
\hline drestricao & $\begin{array}{l}-0.0136 \\
{[0.009]}\end{array}$ & $\begin{array}{l}-0.0144 \\
{[0.010]}\end{array}$ & $\begin{array}{l}-0.0089 \\
{[0.010]}\end{array}$ \\
\hline m_2 & $\begin{array}{l}-0.0166 * * * \\
{[0.001]}\end{array}$ & $\begin{array}{l}-0.0167 * * * \\
{[0.001]}\end{array}$ & $\begin{array}{l}-0.0167 * * * \\
{[0.001]}\end{array}$ \\
\hline m_3 & $\begin{array}{l}-0.0205 * * * \\
{[0.002]}\end{array}$ & $\begin{array}{l}-0.0204 * * * \\
{[0.002]}\end{array}$ & $\begin{array}{l}-0.0210 * * * \\
{[0.002]}\end{array}$ \\
\hline m_4 & $\begin{array}{l}-0.0216 * * * \\
{[0.002]}\end{array}$ & $\begin{array}{l}-0.0215 * * * \\
{[0.002]}\end{array}$ & $\begin{array}{l}-0.0220 * * * \\
{[0.002]}\end{array}$ \\
\hline m_5 & $\begin{array}{l}-0.0229 * * * \\
{[0.001]}\end{array}$ & $\begin{array}{l}-0.0229 * * * \\
{[0.002]}\end{array}$ & $\begin{array}{l}-0.0231 * * * \\
{[0.002]}\end{array}$ \\
\hline m_6 & $\begin{array}{l}-0.0240 * * * \\
{[0.001]}\end{array}$ & $\begin{array}{l}-0.0241 * * * \\
{[0.002]}\end{array}$ & $\begin{array}{l}-0.0242 * * * \\
{[0.002]}\end{array}$ \\
\hline$m_{-} 7$ & $\begin{array}{l}-0.0042 * * * \\
{[0.002]}\end{array}$ & $\begin{array}{l}-0.0057 * * * \\
{[0.002]}\end{array}$ & $\begin{array}{l}-0.0055 * * * \\
{[0.002]}\end{array}$ \\
\hline m_8 & $\begin{array}{l}-0.0124 * * * \\
{[0.002]}\end{array}$ & $\begin{array}{l}-0.0143 * * * \\
{[0.002]}\end{array}$ & $\begin{array}{l}-0.0139 * * * \\
{[0.002]}\end{array}$ \\
\hline m_9 & $\begin{array}{l}-0.0162 * * * \\
{[0.002]}\end{array}$ & $\begin{array}{l}-0.0180 * * * \\
{[0.002]}\end{array}$ & $\begin{array}{l}-0.0176 * * * \\
{[0.002]}\end{array}$ \\
\hline m_10 & $\begin{array}{l}-0.0145 * * * \\
{[0.001]}\end{array}$ & $\begin{array}{l}-0.0161 * * * \\
{[0.002]}\end{array}$ & $\begin{array}{l}-0.0158 * * * \\
{[0.001]}\end{array}$ \\
\hline m_11 & $\begin{array}{l}-0.0187 * * * \\
{[0.001]}\end{array}$ & $\begin{array}{l}-0.0202 * * * \\
{[0.002]}\end{array}$ & $\begin{array}{l}-0.0194 * * * \\
{[0.002]}\end{array}$ \\
\hline$m_{-12}$ & $\begin{array}{l}-0.0004 \\
{[0.003]}\end{array}$ & $\begin{array}{l}-0.0058 * * \\
{[0.002]}\end{array}$ & $\begin{array}{l}-0.0014 \\
{[0.004]}\end{array}$ \\
\hline $\begin{array}{l}\mathrm{N} \\
\operatorname{adj} \cdot \mathrm{R}-\mathrm{sq}\end{array}$ & $\begin{array}{r}99 \\
0.878\end{array}$ & $\begin{array}{r}99 \\
0.865\end{array}$ & $\begin{array}{r}99 \\
0.869\end{array}$ \\
\hline
\end{tabular}

Notas:

- Estimativas de elasticidades apresentadas na média amostral

- Erros padrões estimados em colchetes

- Representações de p-valor: *** $p<0.01, * * p<0.05, * p<0.10$

A primeira alternativa (1), mostra a regressão com todas as variáveis, a segunda (2) mostra a regressão omitindo-se a variável de despesas pessoais e a terceira (3) mostra a regressão omitindo-se a variável de variação do preço de passagem aérea.

\footnotetext{
${ }^{7}$ Fonte: autores.
} 
A alternativa (1), da Tabela 4 apresenta a modelagem completa com todas as variáveis, sendo a melhor das alternativas. As outras alternativas serão comparadas com relação a ela. A alternativa (1) mostra que a elasticidade do preço da passagem de ônibus tem sinal negativo o que faz sentido, pois quando as passagens de ônibus aumentam, menos passageiros viajam (ou viajam menos) de ônibus. O resultado é estatisticamente significante e mostra que com um aumento de $1 \%$ no preço da passagem, perde-se cerca de $1,4 \%$ de passageiros.

Além disso, a alternativa (1) mostra que a massa de rendimento e o preço da passagem aérea tem sinal positivo, o que significa que com o aumento de uma dessas variáveis, o número de passageiros transportados por ônibus interestadual aumenta. Esse resultado é coerente pois, quanto maior a massa de rendimento mais pessoas poderão viajar (ou viajarão mais vezes) e quanto mais cara for a passagem aérea mais passageiros viajarão de ônibus. Ou seja, isso mostra que o avião e o ônibus são bens substitutos.

A elasticidade de despesas pessoais também é positiva mostrando que a discussão feita no item 2.1 sobre a variável é coerente com os resultados encontrados.

As dummies de sazonalidade, com sinal negativo, mostram que todo os meses tem menos passageiros transportados do que o mês de janeiro (base). A dummy do mês de dezembro não tem significância estatística mostrando que seu valor é muito parecido com o da dummy de janeiro.

Apesar de a dummy de restrição do aeroporto de Pampulha não ter significância estatística, observa-se, através seu sinal negativo, que houve uma queda da quantidade de passageiros que viajam de ônibus com a restrição do aeroporto. O aeroporto de Confins fica muito mais distante da cidade do que a rodoviária e do que o aeroporto da Pampulha.

Para analisar os parâmetros de uma regressão linear, retira-se uma variável da regressão e observa-se o que acontece com as outras. Se o valor de alguma variável mudar muito, significa que essa variável e a variável omitida tem forte correlação entre si. A alternativa (2) mostra uma forte correlação entre a variável de despesas pessoais e a massa de rendimento, pois com a omissão da primeira, a segunda ganhou maior significância estatística, além de ter grande variação no seu valor. 
A alternativa (3) mostra certa correlação entre a passagem aérea e as outras variáveis pois o valor delas mudou bastante depois da sua omissão.

Através das elasticidades encontradas na Tabela 4, podem ser feitas outras análises. Por exemplo, pode-se calcular o efeito da entrada da companhia aérea Azul nos aeroportos em dezembro de 2008. Transforma-se a Equação (2) na Equação (3) e com a base de dados podese calcular a quantidade de passageiros que migrou do ônibus interestadual para o avião.

$$
\% \Delta \text { pax }=\varepsilon . \% \Delta \text { passag_aerea }
$$

O $\varepsilon$ é igual a 0,1205 (de acordo com a Tabela 4) e a variação percentual do preço da passagem aérea de outubro de 2009 (depois da entrada da Azul) com relação a outubro de 2008 (antes da sua entrada) é de -33,98\% (informação retirada da base de dados). Ou seja, o preço da passagem aérea caiu 34\% de outubro de 2008 para outubro de 2009. A partir da Equação (3), calcula-se que 4\% dos passageiros migraram do modal de ônibus interestadual. Entretanto, o resultado não é muito preciso, pois a elasticidade da passagem aérea tem pouca significância estatística (com p-valor < 0,10) e além disso, a relação apresentada na Equação (3) é aproximada, pois se refere a variações pequenas.

Para a obtenção de resultados mais precisos, seria necessário que a base de dados de passageiros transportados fosse com relação à Região Metropolitana de Belo Horizonte. Infelizmente só foram encontrados dados referentes ao estado de Minas Gerais, o que pode causar um pequeno viés nos resultados. Por isso, para uma melhor análise da situação seria recomendável obter-se dados somente da RMBH. 


\section{Conclusão}

No Brasil, os principais meios de transporte públicos utilizados em viagens são o avião e o ônibus. Com os baixos preços, a facilidade de crédito e a falta de concorrência de empresas de ônibus em algumas rotas do país, a participação de mercado do transporte aéreo tem aumentado cada vez mais, principalmente em trajetos com maior distância percorrida. Por isso, as operadoras de ônibus devem se esforçar para evitar a perda continuada de passageiros para o modal aéreo, melhorando a qualidade do serviço, aumentando a frequência de viagem e/ou oferecendo descontos nos preços das passagens e serviços de milhagem. Além disso, deve-se conhecer o perfil do passageiro e suas preferências.

Para analisar a competição entre o avião e o ônibus nas viagens interestaduais, foi utilizado um modelo de regressão. Foram estudadas as viagens que tem como origem ou destino a Região Metropolitana de Belo Horizonte, que é um importante pólo do país. Os resultados encontrados podem ser utilizados como base para que os operadores de ônibus possam estudar como aumentar sua atratividade. Por exemplo, através da redução de preços, pois os resultados da modelagem mostram que com um aumento de $1 \%$ no preço da passagem do ônibus, perde-se cerca de $1,4 \%$ de passageiros.

A massa de rendimento, as despesas pessoais e o preço da passagem aérea apresentam elasticidade positiva, o que mostra que um aumento no preço dessas variáveis causa um aumento na quantidade de passageiros de ônibus. 


\section{Referências}

Agência Minas - Notícias do governo do estado de Minas Gerais (2009) Movimento de passageiros em Confins aumentou 1.200\%. 4 de novembro. Disponível em www.agenciaminas.mg.gov.br.

Agência Nacional de Transportes Terrestres - ANTT (2008) Anuário Estatístico. www.antt.gov.br.

Agência Nacional de Transportes Terrestres - ANTT (2011) Pesquisa de satisfação dos usuários de transporte rodoviário interestadual de passageiros. Brasília -DF.

Folha de São Paulo (2011) Com renda em alta, brasileiro já viaja mais de avião que de ônibus. 22 de março.

Gonçalves, M. B., Bez, E. T. e Novaes, A. G. (2007) Modelos econométricos aplicados à previsão de demanda por transporte interestadual de passageiros de ônibus no Brasil. Transportes, vol. 25, n. 1, pp. 24-33.

Gonçalves, M. B., Bez, E. T., Medeiros, H. C., Luz, G. e Philippi, R. C. N. (2006) Um estudo sobre as preferências dos usuários do transporte rodoviário interestadual de passageiros. XX Congresso de Pesquisa e Ensino em Transportes, Rio de Janeiro - RJ.

Instituto Brasileiro de Geografia e Estatística - IBGE (2008) Produto Interno Bruto dos 100 maiores municípios. Disponível em www.ibge.gov.br.

Instituto Brasileiro de Geografia e Estatística - IBGE (2010) Censo de 2010. Disponível em www.ibge.gov.br.

Leal, L. H. C., Orrico Filho, R. D., Ratton Neto, H. X. e Silva, M. A. M. (2009) Análise da concorrência intermodal no transporte interestadual de passageiros no Brasil. XXIII Congresso de Pesquisa e Ensino em Transportes, Vitória - ES.

Moreira, Z. (2010) Baixa concorrência rodoviária faz avião ser mais atrativo. O Tempo. 26 de novembro. www.otempo.com.br.

Programa das Nações Unidas para o Desenvolvimento - PNUD (2000) Ranking do IDH-M dos municípios do Brasil. www.pnud.org.br.

Turolla, F. A., Vassallo, M. D. , Oliveira, A. V. M (2008) Intermodal competition in the Brazilian interstate travel market. Revista de Análisis Económico, vol. 23, n. 1, pp. 21-33. 